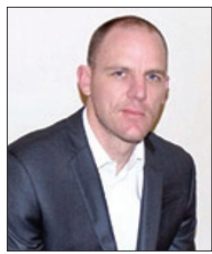

IN THIS ISSUE

In this issue $\mathrm{Dr}$ Brett Duane examines the trends and costs of high concentration fluoride toothpaste prescribing in Scotland.

A number of evidence-based guidance documents in both Scotland and the rest of the $\mathrm{UK}^{1-3}$ recommend the use of high concentration fluoride toothpaste (HCFT) as best practice care, yet its delivery needs to be targeted at those most in need.

Dentists have been allowed to prescribe HCFT since 2006 and the number of items prescribed in Scotland half a decade later had increased almost sixfold. The prescribing of HCFT has risen in a similar way in England, despite the difference in funding of prescribing in both countries: 'For policy makers and commissioners it is important to consider the alternatives for funding HCFT and the potential cost implications.'

Whilst increased prescribing of high concentration fluoride toothpaste is good news for those prone to caries, Brett says it 'should be restricted to people who are at increased risk of dental disease.'

Brett went into dentistry because he liked working with people and was passionate about healthcare. After almost a decade in general practice he started working with Aboriginal people in Australia, where he became interested in public health. Brett's career in public health has taken him to Scotland to work in innovative programmes such as Childsmile and he has since undertaken specialist training in dental public health.

Did you know? Brett is into long distance cycling and will battle his first Ironman triathlon this year.

1. Department of Health and the British Association for the Study of Community Dentistry. Delivering better oral health: an evidence-based toolkit for prevention, 2nd ed. London: $\mathrm{DH}, 2009$.

2. Scottish Intercollegiate Guidelines Network. SIGN 138: Dental interventions to prevent caries in children. Edinburgh: SIGN, 2014.

3. Scottish Dental Clinical Effectiveness Programme. Management of dental caries in children. Dundee: SDCEP, 2010.

\title{
VIEW FROM MY WINDOW
}

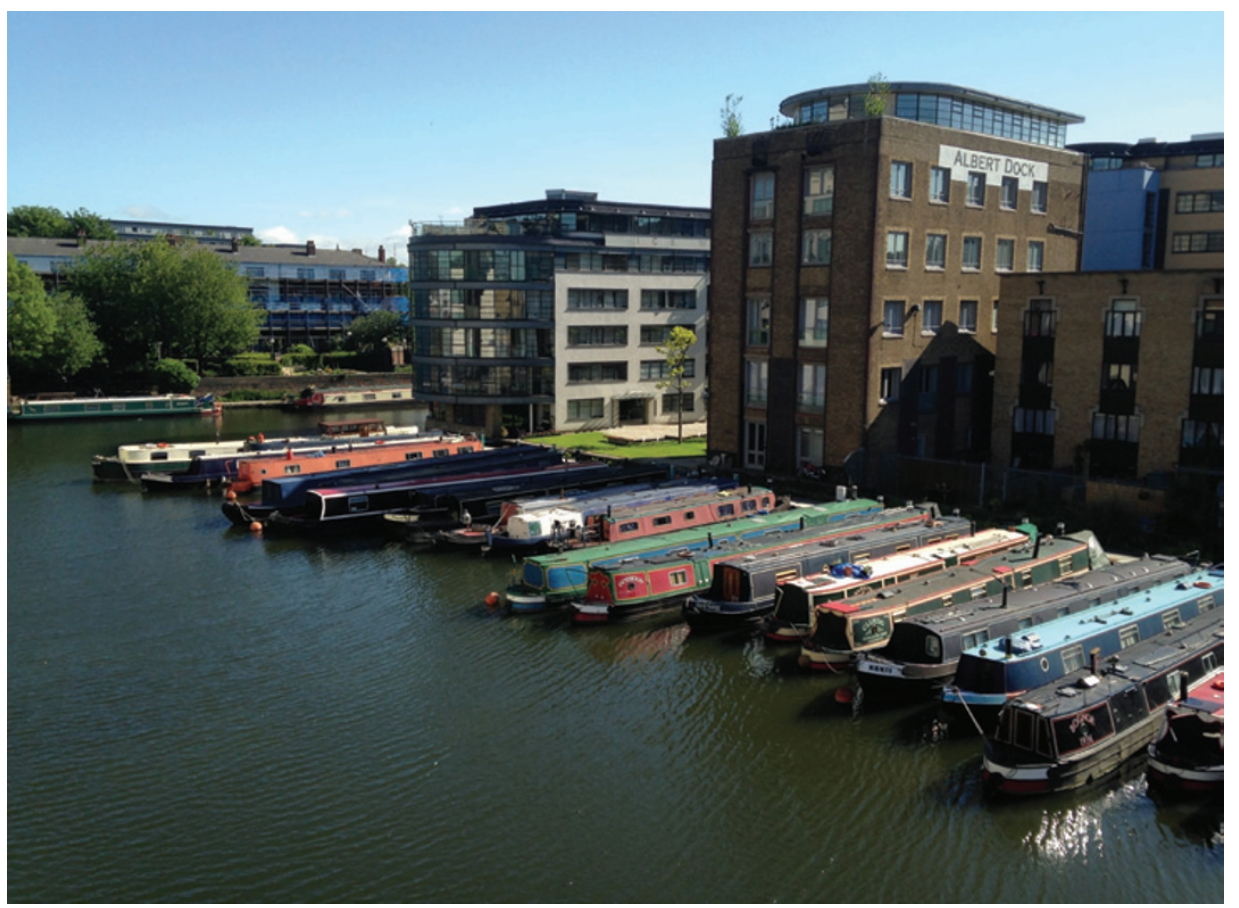

$\mathrm{T}$ This is the view from the British Dental Journal editorial office window. The team behind the $B D J$ are based at Macmillan Publishers in a building overlooking the Regent's Canal in London's King's Cross. The Regent's Canal was opened in 1820 and runs for nine miles from the River Thames at Limehouse to Paddington. Until the 1960s, it was used to carry goods into London. In 2012 the $B D J$ editorial team took a picnic on the Tarporley, Camden's community narrowboat made in 1937.

What is the view from the window of your workplace? Send a high resolution digital photograph of the view from your window to the News Editor, Kate Quinlan, as an email attachment to k.quinlan@ nature.com. Please include your name, job title, and a brief description of the view from your window. We will publish one (or two) in an upcoming $B D J$ news section.

If there are people in your photograph, please confirm that they have given their permission for the photograph to be published in the BDJ.

\section{APPLY FOR NICE ACCREDITATION}

The National Institute for Health and Care Excellence (NICE) is encouraging organisations to apply for NICE accreditation. Accreditation helps health professionals identify the most trusted sources of guidance, driving up the quality of information used by health professionals in decision making, leading to improved patient outcomes.

Sixty guidance development processes have been accredited by NICE since 2009; recent accredited guidance has been produced by the British Society of Gastroenterology; BOSCH Healthcare; and the Royal College of Physicians.

NICE accreditation increases the visibility of an organisation's guidance and advice, and makes it eligible to be considered for the development of NICE quality standards. It promotes the guideline development process as being robust and transparent and allows the NICE Accreditation Mark to be used as an indication of high standard, good quality information.

For further information visit www.nice.org.uk/ accreditation. 